\title{
The counselling and psychotherapy room as a healer
}

\section{space}

\begin{abstract}
The counseling and psychotherapy room is perceived as an actual space in western society which seems likely that psychotherapy and counseling is fulfilling a need which was in the past met by other means. People in the community, family members, neighbors, friends, local doctors, and clergy, usually form emotional and social support systems for individuals. In this Literature review, I hope to establish the different aspects of this healing process. The first part of the Literature Review delineates the relationship between the concepts of extra-sensory perception and healing. Secondly, this review provides an overview of the importance of Self-knowledge as part study of the healing process in the counseling and psychotherapist room. Finally, in part three, a typological psychotic view of the subject will be given. This development shifts the field of scientific enquiries into a new period; one that is separated from the past by its recognition of the psychiatric, psychological and medical field which influence in a direct and indirect way the work carried out in the counseling room as a healing space.
\end{abstract}

Volume 9 Issue I - 2018

Giselle Marie Cara

Department of Psychology, Nottingham University, UK

Correspondence: Giselle Marie Cara, Department of Psychology, Nottingham University, UK, Email cara23। @live.com

Received: April 09, 2015 | Published: January 09, 2018

\section{Foreword}

The preparation for this assignment has helped me to think profoundly about my life, values, beliefs and learning in the field as Psychotherapist. I realized that the reason why I chose to take a close look at the psychotherapy and counseling room as a healer space is because of my passion for understanding myself, human existence and the phenomenology around the topic. When I watch family, friends, and people in society living their lives, trying to be successful: emotionally, financially, professionally and any personally matter, I realized that I was and still am passionate about understanding human relations and existence. I have looked closely at this aspect from a very young age. I believe I am contributing to all human beings living in a more peaceful, ethical world and consequently helping the development of our civilization as whole, which so many times society turns a blind eye to. I hope to continue and finalize this perspective.

\section{Introduction: understanding the healing concept in the psychotherapy and counselling room}

The counseling and Psychotherapy room is perceived as an actual space in western society which seems likely that psychotherapy and counseling is fulfilling a need which was in the past met by other means. People in the community- family members, neighbors, friends, local doctors, and clergy, usually form emotional and social support systems for individuals. Counselling and psychotherapy is to be found in many guises in society and to add to the complexity, there are many formal schools of counseling and psychotherapy which are informed by their own particular theoretical framework. These can, however, be identified and understood by the three core approaches of behavioural, analytical and humanistic. I begin this piece of work by following the humanistic view, which is open to new ideas and perspectives. ${ }^{1,2}$ Since my analysis proposes to look at the counselling and psychotherapy room as a healing space, it is important to look at the very concept of healing. Sternberg ${ }^{3}$ mentions in his literature that history of natural healing goes back to the beginning of the civilization. Science and research have been tracking back information in history, helping explain the phenomena in human everyday life in order to understand and improve our society. The Counselling and Psychotherapy room has been a place where many phenomena actually take place through healing practice. However many arguments and disagreements have been accompanying this path of discovery so far and many times bringing us back to same place where the search started. The word 'healer' is the agent noun of 'heal'; a person who heals, especially through faith. An expression only used years ago with ritualistic or religious connotations. Healing was not a concept considered as a science based subject. ${ }^{4}$ Nevertheless, looking closely at the aspect of phenomenology, there are dual perspectives which science still looks at closely. Firstly, when we are present as counsellor, psychotherapist or as healer present at the moment; and secondly, when we perceive, translate and understand the actual subjective experience phenomenon process of the moment. Often, these perspectives are encountered as holistic. In the past, rituals were used to bring some type of answers related to a specific physical and mental health issues in a more spiritual concept. I believe this concept is moving forward to experiences in the psychotherapy and counselling room. For that reason some counsellors, psychotherapists and even doctors have begin to refer to themselves as 'healers', since they experience such phenomena.

We are getting closer to an era of broader flexibility and integration in the counseling room and in the health care field. It encompasses the understanding of as many subjects and ideas as possible in order to achieve better results for every individual. For instance, theorists such as Buzan ${ }^{5} \&$ Jaynes $^{6}$ have turned this range of notions and subjects into set of ideas about two different ways of consciousness, and then two different kinds of people, each specialized in one of these forms. In addition to the two ways of consciousness mentioned above, the term 'dichotomies' has been used to describe this flood of speculation, which ignores the fact that, no one in the two hemispheres is not separated from the other. In this case, the healer and the client in the counselling and psychotherapy room. They are in constant cooperation, ${ }^{7}$ which explain the relationship between psychotherapist and client through the healing process. However, a possible alternative explanation is given by Trevarthen:

As example we can look at the Brain which is adapted to create and maintain human society and culture by two complementary conscious systems. Specialized in the two hemisphere generate a dynamic 
partnership between the intuitive, on another side, and the analytic or rational, on another side, in the mind of each person. ${ }^{8}$ Together the intuitive and the logical work in favour of human development, fostering creativity and creating newer perspectives in life. This occurs through the interaction of the client and the psychotherapist within the space of the counselling and psychotherapist room, as their dialogue triggers a healing moment. In this essay, I hope to establish the different aspects of this healing process. The first part of the essay delineates the relationship between the concepts of extra-sensory perception and healing. In this section, the healing process is seen more as a phenomenological subjective experience. Hence, nowadays, the healer concept is also used in the physical professional scientific research field in a phenomenological perspective. Secondly, this essay provides an overview of the importance of Self-knowledge as part study of the healing process in the counselling and psychotherapist room. In addition, the counsellor's and psychotherapist's Selfknowledge is also foregrounded in this part of the analysis, as it plays a significant role in creating an atmosphere conducive to healing in the counselling room. Finally, in part three, a typological psychotic view of the subject will be given. This development shifts the field of scientific enquiries into a new period; one that is separated from the past by its recognition of the psychiatric, psychological and medical field which influence in a direct and indirect way the work carried out in the counselling room as a healing space. In the course of this essay I will also look at individuals with extra sensorial perception and spiritual abilities, who, many times have been labelled as psychotic and given medicine without their spiritual needs being addressed or catered for. In this way, some of the typologies aspects also will be covered. ${ }^{9,10}$

Moreover, professionals in the health care system, such as nurses, psychiatrics, psychologists, counsellors and professionals from complementary and Alternative Medicine who have also experienced these phenomena and felt they had too much to contribute in the healing environment will also be discussed.

This journal will also examine those whose words fall on deaf ears for lack of hierarchical or political importance. The aim is to seek more equal and fair means of accessing and giving help and suggesting ideas and support for a renewed form of education which all individuals would benefit from; not only in the psychotherapy and counselling room but also in various aspect of life through the concept of multiple intelligences and abilities as was suggested by Gardner. ${ }^{11}$

\section{Part 1: Extra-sensory perception and healing}

Spirituality which comes from Latin spiritus, meaning breath of life, is a way of being and experiencing that comes through awareness of a transcendental dimension and that is characterized by certain identifiable values in regards to self, other, nature, life, and whatever one considers to be the Ultimate. ${ }^{12}$ Elkins looks at the notion of extra-sensory perception and its relationship with healing through the lens of spirituality, underlining the significance of awareness, of intuition. Jung ${ }^{13}$ analysed the concept of the collective unconscious related to extra-sensory perception as translated by dreams. He carried out the analysis of his own dreams, his clients' dreams, hallucinations, fantasies, visions, and delusions of psychotics. Jung discovered that the human psyche has access to images and motifs that are truly universal. ${ }^{14}$ Based on Jung's experiences related to the collective unconscious Dunne has demonstrated that most of his finds where based on his realizations and work done on his own dreams. Exploration on the subject continued with an avalanche of experiential techniques of psychotherapy and spiritual practices of all kinds, from Gestalt therapy to transcendental meditation among therapists and lay people in the 1970s and 1980s. Interestingly, these facts can be found in much earlier ages. The mythology, folklore, and art of different cultures widely distributed not only across the globe but also throughout the history of humanity. ${ }^{15,16}$ I believe that not all people perceive this awareness in relation to the subjective and phenomenological world in the same way or collective unconscious in the words of Jung. At no point during my years of practice have I ever wished to call attention to this particular aspect, but every day I understand gradually that it is a natural process that can and will happen more often than not. More times than anticipated, conflicts can emerge if therapy is not carried out professionally. For instance, there is an enduring perception that practitioners of psychological therapies and some counsellors are insensitive to the spiritual values of clients. ${ }^{17}$ One possible reason is that the phenomenon many times is perceived as a religious concept. Many people do not pay attention to these factors, everyday life experiences, worries, occupations and responsibilities blind people to their own intuition and lead them to focus on the logical and rational side. One example of how subjective experiences can be thus misinterpreted is through the existence and experience of visual illusion and hypnosis.

For example, in this picture of Munch ${ }^{18}$ Figure 1, there is a dual communication happening also in the way information is passed on and related. How an individual looks at a picture is closely related to his/her own experiences since individuals see things in different perspectives and dualities. Communication is offered based on the level of awareness of the communicator. The information can be passed on in a way the individuals choose the information to be transmitted, that is according to each individual experience values and beliefs. This information is shared in multifarious ways and two of these are cognitively and through our verbal communication, which is informed by many different variables such as tone of voice and body language.

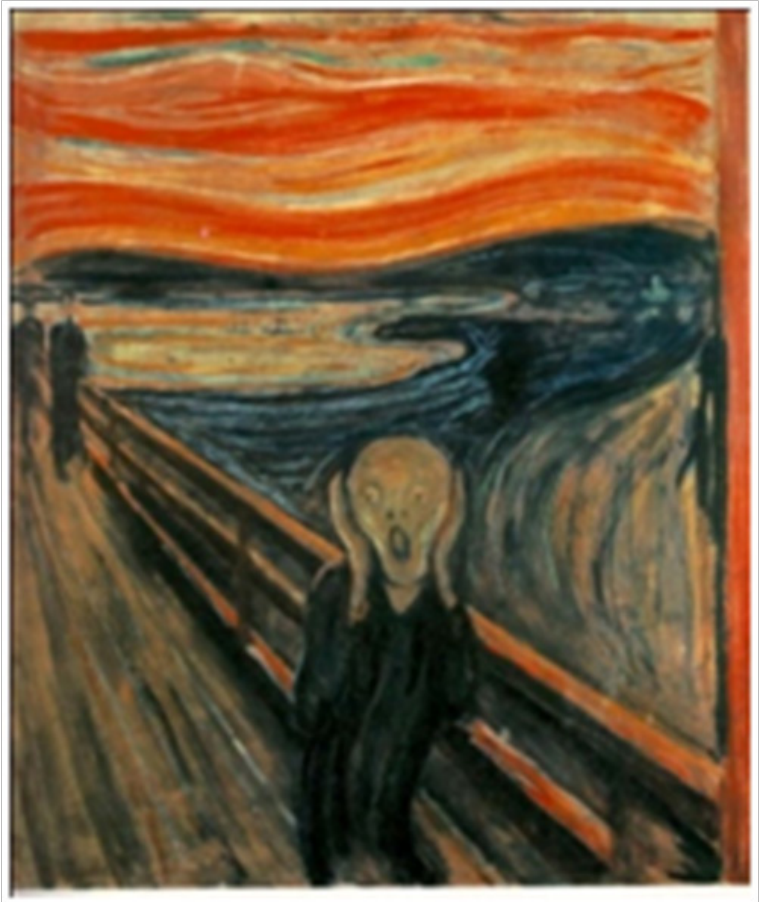

Figure I Munch Edvard (I893) The Scream.

Finally, the role of psychotherapist and counsellor is also to provide an environment that enables the client to work towards living 
in a more resourceful and personally fulfilling way. One way to provide this environment is getting closer to know ourselves, and then consequently understanding and getting closer to understanding those around us, much like the law of causation: 'If I know myself, I can proceed to get to know you'. It is a first step to moving toward a form of integration. Moreover, integrity, respect and impartiality are basic values which are demonstrated throughout the counselling process. ${ }^{19}$ When this procedure is well balanced and performed healing occurs naturally in a phenomenological way.

\section{Part 2: Self-knowledge and healing}

Getting to know ourselves deeply in order to reach such cohesion with all can be done in many different ways such as meditation, counselling sessions, psychotherapies, personal reflections or simply living life itself. During these stages feelings of oneness with the entire universe can emerge.

Visions and images of distant times and places, sensations of vibrant currents of energy going through our bodies, vivid lights and fear of insanity and death are not uncommon. These are extra-sensory experiences that most human beings undergo at some points in their life. This involves trying to respect and contributing to a peaceful unification among beliefs and experiences among human beings in a way which is congruent to all. ${ }^{20}$ Inexplicable things happen in life. Individuals emerge successfully from different levels of difficulties and processes during their lifetime. Theorists search for ways to help society to live a better life in a way which can continue the development of human kind and at the same time, and offer healthier ways to maintain life. Many of these inexplicable cures and resolution comes from individuals who call themselves 'healers' ${ }^{21}$ The reason why through healing ourselves we can heal others is related to the aspect that we create a self-fulfilling level of awareness which can evidently be transmitted to the client. If I have a profound understanding of a specific topic in a focus at deep level, and at the same time understand how I have reached this level of understanding, it becomes easier to guide others through their own process of realisation. This process is specific to each individual, however it can move towards a potential integration. As Jung ${ }^{13}$ himself demonstrated through his self-realisation and self-analysis, it is extremely important to have self-knowledge in the counselling room in order to lead the client to the healing process. However, it is just as important for the client to co-create this with the counsellor. In a certain way, this becomes a partnership of learning and teaching through phenomenological experiences. Even if the healing is not ideal for all, nonetheless the pure intention behind is of even greater importance. Placebo effect in the client's eyes have shown to be also responsible for many healing in our society. ${ }^{22}$

The intention in this piece of work is not to convince if healing is a true process or not. It is to suggest that counselling, psychotherapy or Complementary and Alternative Medicineaim to improve and develop human existence in a more ethical and respectful way. Consequently, it is important have more committed options systems, which cater to all and not only to a selected group, and hopefully one day, to have a common awareness about who we are. Ideally it is to bring a point of view which brings together society as a big family, a cohesive group and not separated into small groups. In that way consequently we can live in a more peaceful harmonious life as whole.

Nowadays some knowledge in the field of extra sensorial healing in therapy and counselling field has been analysed closely. Historically some individuals in these groups have not had their grief needs acknowledged, addressed or accommodated. Still, the way information is being passed on is holding back newer practitioners professionals in health care to maintain their level of motivation towards research in the field. I believe this is due to the commercialization of training courses and the academic field's inability to overcome the hierarchal level of knowledge. They are held back by the blind fear of death, aging or any information, sensation which is received by the unknown. However this unknown is a fact which is present in healing and any other phenomenological experiences involved in various mystical traditions rituals of the world. These traditions vary among indigenous rituals and meditations. Evan ${ }^{23}$ in his article explains that healing may be realized through an emotional corrective relationship. His argument is based on dialogical Gestalt therapy, ${ }^{24}$ which emphasizes a horizontal (equal) relationship between the therapist and clients. He also relates that Gestalt and dialogue encounter is described in terms of three major characteristics: inclusion, presence and commitment to the between. ${ }^{25}$ It is essential that therapists and counsellors understand the dynamic of healing in the counselling room. Gardner states in his book Fiveminutes for the future, ${ }^{26}$ the thought of respect will only be present in human beings when we accept the concept that we all have many different types of intelligences, each one of them is related to how individuals deal with emotional intelligence. Recently Gardner also saw the greater importance and connection in society's emotional intelligence and spirituality.

\section{Part 3: Typological psychotic view}

Many psychiatrists, psychologists, psychotherapists and counsellors are studying modern western science searching for newer perspectives and answers including for themselves. I started to read past scientific papers and decried the unfair misjudgement of science on anyone experiencing such extreme mental and physical phenomena that would immediately be labelled psychotic by most westerners. ${ }^{27,28}$ The number of individual experiencing these and similar to those experiences described above are increasing. However we are not sure if is also increasing because individuals are less fearful of these diagnostic categories, since they are also being seen as different perspectives. Research has shown that some patients worry about sharing their true feelings. This concern is connected to western society, based on diagnostic given by professionals in Health care. The concern about sharing how they feel is due to the fact of fear of been labelled or diagnosed. In western society individuals who demonstrated perception of any type of influences, or different forms of thinking and perceptions of the world, have been diagnosed by professionals for having some form of disorder or dysfunction. However the greatest scientists, like Einstein for example, and individuals who made a difference in our society, were also somehow excluded by society for being different and not fitting in as they were not what was considered to be 'normal'. Nowadays research is facing different issues including the possibility that an extra-sensory experience might have incomprehensible elements to it. Currently individuals are emerging from these extraordinary experiences; many with an increased sense of well-being and higher levels of functionality in daily life. In many cases long lasting emotional, mental and physical problem are healed in the process. Some individuals going through these feelings call themselves being 'healed' or those helping individuals going through the process call themselves 'healers'.

The group of mental disorder known as psychoses represents a great challenge and enigma for western psychiatry and psychology. These conditions are characterized by a deep disruption of the ability to perceive the world in normal terms, to think and respond emotionally in a way that is culturally and socially acceptable, and to behave and communicate properly. Many years and much effort were required to sensitize psychiatrists, psychologists, counsellors and therapists to 
cultural contributions to their patients' difficulties. Some critics (Ho \& Ho 2007, Helminiak 2001), influenced largely by anthropologists and other social scientists, stated that the doctors decontextualized their patients. But that is history. There is now a well-established society of psychiatrists focused on the study of culture and behaviour, and, after an initial flurry of resistance, the society now includes social scientists among its members. Recent years have also seen an abundance of books on cultural competence and related issues for clinicians. This broadens the field and stakes out its own territory as it includes the traditional healing practices of groups around the globe, and even touches on contemporary alternative and integrative healing methods.

For some of the disorders in the category of psychosis, modern science has found underlying anatomical, physiological, or biochemical changes in the brain or in the other parts of the organism. These subgroups are referred as organic psychosis; and belong unquestionably in the domain of medicine. However, for many other psychotic states, no medical explanation has been found in spite of the focused effort of generalization of researchers from various fields. Despite a general lack of results in the search for specific medical causes, these so-called functional psychoses are usually put into the category of mental diseases whose causes are unknown. It is this group which remains our specific focus in this discussion. Storr (1997) suggests that labels should be dropped because each individual has their own set of circumstances and experiences that are different from other people's and what is acceptable to one society might not be 'normal' in another one. He goes further to talk about spirituality and pathology:

My own feelings are that the distinction 'Spiritual' versus 'pathological' should be dropped. Everyone is liable to have deeply irrational experiences or hold deeply irrational beliefs that may be destructive or may be life enhancing. Psychiatric diagnostics must include reference to the subject's personal relationship and his place in society as well as taking cognizance of his beliefs and mental experiences as an isolated individual. Otherwise we might condemn saints as psychotics, while treating serial killers as sane (1997). Experiences from counsellors, healers and psychotherapist which involve premonition, visions or any another phenomenological aspect have occurred in sessions. Concluding the mystical nature of such experience in no ordinary states of consciousness puts them automatically into the category of pathology, since extra-sensory perception is not seen as legitimate dimension in the exclusively material universe of traditional science.

\section{Conclusion}

This paper has identified and explored the challenges inherent in developing psychotherapy and counselling in health care service throughout, and a range of specific issues have emerged. It is not possible for pure science to cater for the needs of all clients and those who experience extreme or altered states are in danger of being labelled and pigeonholed into categories, whereas a holistic, and alternative approach to therapy could have benefitted them. This absence of understanding on the field indicates the needs for development in the area. Additionally is suggested here that further studies done in the psychotherapy and counselling room as a healer space, occurs through a simple written, pictorial evaluation sheet. This could be used both before and after consulting, in an effort to establish and explore the clients' perspectives and experiences during the healing process. The client's histories and experiences are also important, as they offer valuable insight into unique personal experience. The invitation for clients to tell their stories will be an important element of the research, and such participatory approaches. ${ }^{29}$ People seek answers. Thus there are still questionings of the rules of the systems related to awareness in the field. If many of these rules are not followed in a set of values and belief in a system. Many forms of unconscious control can be done to the individual without a contract between both parties. If people have a certain level of self-awareness and ways to bring balance to the self, it can be a means to be strong against those interferences. Human beings are necessarily self-healing psychologists who develop their own self adjustment processes; a more systematic means of facilitating the development of the processes is portrayed, re-authored photo self-narratives. Each client brings their own views and follows their own beliefs of what healing means are a very important issue in order to benefits and results of the healing. ${ }^{30-33}$

\section{Acknowledgements}

None.

\section{Conflict of interest}

Author declares there are no conflicts of interest.

\section{Funding}

None.

\section{References}

1. Nelson JR. Practical Counselling and Helping Skills. ( $4^{\text {th }}$ edn), Cassel, UK. 1997.

2. McLeod J. An Introduction to Counselling. ( $2^{\text {nd }}$ edn), Open University Press, UK. 1998.

3. Sternberg RJ. Wisdom: its nature, origins and development. Cambridge University Press, India. 1990. p.1-352.

4. Singer J. Boundaries of the Soul: The Practice of Jung's Psychology. Prism Press, UK. 1995.

5. Buzan T. Use both sides of your Brain. EP Dutton, USA. 1976. p.1-160.

6. Jaynes J. The origin of consciousness in the Breakdown of the Bicameral Mind. Houghton-Miffin, USA. 1976. p.1-479.

7. Pinker S. How the mind Works. Allen Lane, UK. 1998.

8. Trevarthen C. Split brain and the mind. In: Gregory R (Ed.), The Oxford companion to the Mind.Oxford University Press, UK. 1987. p.740-747.

9. Wilber K. Upfrom Eden: A transpersonal View of Human Evolution. Wheaton, Quest books, USA. 1996.

10. Zuercher S. Enneagram Spirituality: From Compulsion to Contemplation. South Bend, Ave Maria Press, USA. 1992.

11. Gardner H. Frames of Mind: The Theory of Multiple Intelligences. Basic Books, USA. 1985.

12. Elkins DN, Hedstorm LJ, Hughes LL, et al. Towards a humanistic Phenomenological spirituality. Journal of humanistic Psychology. 1988;28(4):5-18.

13. Jung CG. The Archetypes and the Collective Unconscious Volume 9, Part 1. Of the collected Works of CG Jung. Routledge \& Kegan Paul, UK. 1959. p.1-452.

14. Dunne Clare. Carl Jung: Wounded Healer of the Soul: An Illustrated Biography. Continuum International Publishing Group, UK. 2002. p.1-248.

15. Angermann K. Gestalt Therapy for eating disorder. The Gestalt Journal. 1998:21(1):19-47. 
16. Gillie M. Shame and Bulimia: A Sickness of the soul. British Gestalt Journal. 2000;9(2):98-104.

17. West W. Integrating conselling, psychotherapy and healing: an enquire into counsellours and Psychotherapists whose works includes healing. British Journal of Guidance \& Counselling. 1997;25(3):291-311.

18. Edvard. The Scream - Location: National Gallery Oslo Norway Dimensions $91 \mathrm{~cm}$ x $73.5 \mathrm{~cm} .1893$.

19. Beutler L, Bergan J. Value Change in Counseling and Psychotherapy: A Search for Scientific Credibility. Journal of Counseling Psychology. 1991;38(1):16-24.

20. Kalwait H. When Insanity is a Blessing: The message of Shamanism. Originally appeared under the title: Suffering Kills, Suffering Enlivens: Sickness and self-healing in Dream time and the Inner space: The world of Shaman. Shambala Publishing, USA. 1988

21. Dabrowski K. Positive Disintegration. Boston: Little, Brown and Company, USA. 1966.

22. Wall PD. Pain and the placebo response. Ciba Found Symp. 1993; 174:187-211.

23. Evans KR. Healing Shame: A Gestalt Perspective. Transactional Analysis Journal. 1994;24(2):103-108.

24. Perls F. In and Out the Garbage Pail Lafayette. Real People Press, USA. 1969.
25. Yontef GM. Recent trends in Gestalt therapy in the United States and what we need to learn from them. The British Gestalt Journal. 1991;1(1):5-20.

26. Gardner H. Five minutes for the future. Boston: Harvard Business Press, USA. 2008.

27. Schiff TJ. Being Mentally Ill. Weidenfeld \& Nicholson, UK. 1966.

28. Furman A, Bower P. A comparison of academic and lay theories of schizophrenia. British Journal of Psychiatry. 1992;161:201-210.

29. McClimens A. Participatory Research with people who have Learning Disability: Journey without a map. Journey of Learning Disability for Nursing, Health and Social Care. 1999;3(4):219-228.

30. Golsworthy, Coyle. Religion and Spiritual Belief and the search for meaning in the bereavement. An international Journal of Psychology and Psychotherapy. 1999. p.1-17.

31. Moodley R, West W. Integrating Traditional Healing Practices into Counseling and Psychotherapy. Thousand Oaks, CA: Sage Publications, UK. 2005.

32. Quackenbos S, Privette G, Klenz B. Psychotherapy and Religion: Raproachement or antithesis?. Journal of Counselling \& Development. 1996;65(2):82-85.

33. Rogers CR. Encounter Groups. Penguin, UK. 1971 